\title{
Consórcio Mestral
}

\section{GESTÃO DAS INFORMAÇÕES SOBRE TREINAMENTOS DE AGENTES DE SEGURANÇA PÚBLICA}

\author{
João Daniel Coelho Júnior ${ }^{1}$
}

\begin{abstract}
Resumo: Os órgãos de segurança pública têm um papel fundamental na sociedade visando - bem-estar e segurança de todos. Os agentes de segurança pública devem ter competências (capacidades técnicas, físicas e psicológicas) em pleno vigor para servir a sociedade com êxito, sendo o treinamento continuado um elemento fundamental para toda sua vida laboral. A falta de treinamento constante destes agentes poderá gerar grandes perdas, incluindo o bem mais precioso: a vida. O objetivo geral deste projeto é estudar as formas de gerenciamento das informações de treinamento continuado num órgão de segurança pública federal específico, bem como propor um sistema de informação que auxilie os gestores no controle e auxilie em correções de eventuais falhas. Trata-se de uma pesquisa exploratória para diagnosticar e identificar a atual situação de um órgão federal de segurança quanto ao registro e gestão das informações de treinamento dos servidores. $\mathrm{Na}$ etapa de diagnóstico serão realizadas entrevistas semiestruturada com gestores de órgãos centrais em Brasília responsáveis pelas capacitações e desenvolvimento tecnológico. Além disto, a aplicação de questionário estruturado com perguntas fechadas e abertas, com foco em algumas unidades regionais (superintendências) por amostra. Um estudo de benchmarking estadual é pretendido também na etapa inicial. A revisão teórica do projeto centra-se em descrever fluxos informacionais de Gestão de Pessoas por Competências e a relação com os conceitos de "informação-como-processo" e "informação-comoconhecimento", e os paradigmas cognitivo e social. Espera-se com a conclusão deste estudo, contribuir para a aplicação da gestão da informação nos treinamentos de órgãos de segurança pública, indicando práticas e instrumentos para a sua implementação.
\end{abstract}

Palavras-Chave: Ciência da Informação. Gestão de Informação. Mapeamento de Competência. Treinamento. Segurança Pública.

\section{INTRODUÇÃO}

Atualmente as organizações precisam ser cada vez mais eficientes para atingir seus objetivos e ser úteis para sociedade. Nestes termos, o capital humano é um bem cada vez mais valorizado pelas organizações, seja este envolvido para contribuições no planejamento estratégico, nas inovações, produção, entre outras atividades, estando presente em todas as áreas das organizações. Chiavenato (2004) afirma que são as pessoas que dirigem e controlam as organizações, bem como as fazem operar e funcionar. Não existe organização sem pessoas que são

\footnotetext{
${ }^{1}$ João Daniel Coelho Júnior, mestrando no Programa de Pós-Graduação em Ciência da Informação da Universidade Federal de Santa Catarina, orientado pela Profa. Dra. Ana Clara Candido. E-mail jdcj.br@gmail.com.
} 
suas peças fundamentais. O sucesso e continuidade das organizações depende das pessoas.

Dentro dos órgãos de segurança pública, seus servidores/agentes devem ter competências (capacidades técnicas, físicas e psicológicas) em pleno vigor para servir a sociedade com êxito. Para alcançar as competências e o máximo desempenho na sua atividade, eles necessitam de treinamento e capacitação continua durante toda sua vida laboral. A falta de treinamento constante destes agentes poderá gerar grandes perdas, incluindo o bem mais precioso: a vida, conforme notícia de Guimarães (2010).

Em 31/12/2010 o Ministro de Estado da Justiça e o Ministro de Estado Chefe da Secretaria de Direitos Humanos da Presidência da República publicaram a Portaria Interministerial $n^{\circ} 4.226$, estabelecendo Diretrizes sobre o Uso da Força pelos Agentes de Segurança Pública, devendo obrigatoriamente serem observadas por órgãos de segurança pública federais.

Entre as diretrizes obrigatórias está a "habilitação para o uso de cada tipo de arma de fogo (...) e treinamento específico, com previsão de revisão periódica mínima". Por norma legal, pode-se afirmar que uma das competências necessárias para o agente de segurança pública é a habilidade de manipular a arma de fogo que costuma portar. Por força desta norma os agentes de segurança devem ter um treinamento continuado específico para armas de fogo para manter as habilidades necessárias desta competência.

Esta pesquisa pretende estudar formas de gerenciamento das informações de treinamento continuado num órgão de segurança pública federal específico, bem como propor um sistema de informação que auxilie os gestores no controle e auxilie em correções de eventuais falhas.

\section{Delimitação do problema}

O principal problema do estudo é como é feito o gerenciamento das informações de treinamento continuado num órgão de segurança pública federal específico.

É desconhecida a existência de um padrão para registro das informações sobre os treinamentos dos servidores deste órgão. Nem mesmo existe algum sistema que facilite o gerenciamento destas informações, bem como eventuais 
correções necessárias para manter o efetivo da instituição com um treinamento mínimo necessário.

Este projeto terá como foco os treinamentos referentes às armas de fogo, tendo em vista contribuir para o atendimento eficiente da Portaria Interministerial 4.226/2010. Entretanto, os resultados obtidos também poderão ser utilizados e adaptados para outras competências e áreas de treinamento, como por exemplo: defesa pessoal, táticas operacionais, primeiros socorros, etc.

É necessário fazer uma diferenciação entre os cursos e capacitações ministrados pela entidade de ensino central deste órgão e os treinamentos periódicos realizados pelos agentes de segurança pública. Os cursos, geralmente, são capacitações onde os agentes aprendem um novo conhecimento ou recebem uma grande atualização sobre um determinado tema. Os treinamentos periódicos costumam ocorrer de forma descentralizada, no local de trabalho dos agentes, com objetivo de manter ativo os conhecimentos e habilidades aprendidos em cursos e capacitações anteriores.

\section{Objetivo geral}

- Propor um sistema de gerenciamento das informações de treinamento continuado de armas de fogo para um órgão federal de segurança pública.

\section{Objetivos específicos}

- Identificar como ocorre o registro dos treinamentos dos servidores deste órgão de segurança pública federal.

- Desenvolver ou adequar o fluxo de informações de treinamentos, bem como seu processo dentro do órgão.

- Projetar sistema de informação para gestão das informações de treinamento.

\section{REVISÃO DE LITERATURA}

A gestão de pessoas tem desempenhado um papel relevante na performance das organizações e tem acompanhado a evolução dos modelos de administração. 
Por exemplo, o modelo de Gestão de Pessoas por Competências foi desenvolvido no final da década de 80 e pode ser considerado recente e em expansão (FISCHER, 2002). Tratando-se de um modelo de gestão com vários fluxos de informacionais, este estudo irá relacionar este modelo com a Ciência da Informação.

\section{Gestão de pessoas por competências}

Visando atingir seus objetivos institucionais, as organizações sempre estão em procura de modelos de gestão que gerem resultados mais eficientes. Diante desta procura contínua e sabendo que as pessoas são peças fundamentais para que as organizações alcancem seus objetivos, existe um aprimoramento contínuo das organizações em busca de uma gestão de pessoas mais eficiente.

No início do século $X X$ a gestão de pessoas ocorria no Departamento Pessoal, onde os funcionários eram administrados como custo. Ao longo dos anos foram desenvolvidos outros modelos de gestão, como: Gestão do Comportamento (anos 30, com o início da utilização da psicologia na gestão de pessoas), Modelo Estratégico de Gestão de Pessoas (anos 70, com a vinculação da gestão de pessoas às estratégias das organizações) e, posteriormente, o modelo estratégico articulado por competências (FISCHER, 2002). O modelo de Gestão de Pessoas por Competências é o foco deste projeto.

Antes de descrever propriamente o modelo, precisa-se entender o que é competência. Segundo Ferreira (1999), competência é “(...) 2. Qualidade de quem é capaz de apreciar e resolver certo assunto, fazer determinada coisa; capacidade, habilidade, aptidão, idoneidade. (...)", entre outros significados. Analisando vários autores, Fleury e Fleury (2001, p. 3) afirmam que "o conceito de competência é pensado como conjunto de conhecimentos, habilidades e atitudes (isto é, conjunto de capacidades humanas) que justificam um alto desempenho", sendo as competências como recursos em estoque que um indivíduo detém.

As competências também podem se relacionar em vários níveis: das pessoas (a competência do indivíduo), das organizações (core competences) e dos países, relacionadas aos sistemas educacionais e formação de competências (FLEURY; FLEURY, 2001). Neste contexto, as competências do indivíduo promovem e mantem as competências das organizações, que por sua vez são influenciadas pelas competências das nações em que estão inseridas. 
Rabaglio (2001, p. 3) também define competência como "um conjunto de conhecimentos, habilidades e atitudes específicas que permitem ao indivíduo desempenhar com eficácia determinadas tarefas, em qualquer situação, de forma peculiar". Ela também explica sobre o conjunto Conhecimento, Habilidade e Atitudes $(\mathrm{CHA})$, conforme quadro 1 a seguir. "Conhecimento" e "Habilidades" estão relacionados com as competências técnicas, enquanto "Atitudes" está relacionada com competências comportamentais.

Quadro 1: Conhecimentos, Habilidades e Atitudes

\begin{tabular}{|c|c|c|}
\hline Conhecimentos & Habilidades & Atitudes \\
\hline & & $\mathbf{A}$ \\
\hline Saber & Saber fazer & Querer fazer \\
\hline $\begin{array}{l}\text { Conhecimentos técnicos } \\
\text { específicos, escolaridade, } \\
\text { cursos, especializações, } \\
\text { etc. }\end{array}$ & $\begin{array}{lr}\text { Experiência } & \text { Prática, } \\
\text { domínio } & \text { nos } \\
\text { conhecimentos técnicos. } \\
\text { Implica ter praticado o } \\
\text { conhecimento. }\end{array}$ & $\begin{array}{l}\text { Ter atitudes compatíveis } \\
\text { para atingir eficácia em } \\
\text { relação aos } \\
\text { conhecimentos e } \\
\text { habilidades adquiridos ou } \\
\text { a serem adquiridos. }\end{array}$ \\
\hline
\end{tabular}

Fonte: Rabaglio, 2001, p. 6

Compreendido o que é competência, passamos ao próprio modelo de Gestão de Pessoas por Competências. Segundo Ruano (2003) a Gestão de Pessoas por Competências é um modelo estratégico cujo objetivo é a gestão de pessoas e da organização, tendo uma atuação voltada para resultados, auxiliando as organizações a atingir seus objetivos. Neste modelo é necessário a definição das competências da empresa e de seus colaboradores, visando que ambos sigam na mesma direção e atinjam os resultados esperados. A definição das competências é o cerne do modelo. Uma vez definidas, elas servem como fonte de informação para alimentar a área de Recursos Humanos e sistemas relacionados. Munidos destas 
informações, é possível desenvolver uma estratégia para a gestão de pessoas utilizando sistemas de avaliação mensuráveis.

Coelho (2004) afirma que no modelo de Gestão de Pessoas por Competências deve haver uma maior responsabilidade pela aprendizagem por parte dos gerentes e colaboradores. Ele acredita que é preponderante para as organizações que buscam melhorar seus níveis de desempenho, desenvolver um programa de capacitação que tente adequar ou eliminar as diferenças existentes entre as competências desejadas (ideais) e as competências apresentadas (reais). Esta diferença (lacuna, gap) entre as competências que a organização deseja (ideais) e a dos indivíduos (reais) deve ser reduzida ao máximo mediante capacitação continuada e treinamento constante. Mediante capacitação e treinamento as competências reais dos colaboradores tendem a crescer com o objetivo de atingir o mesmo nível das competências ideais. No Gráfico 1 abaixo é possível identificar que as competências ideais das organizações também estão em constante mudança e evolução, se adequando as realidades em que a organização está inserida.

\section{Gráfico 1: Competências Reais x Competências Ideais}

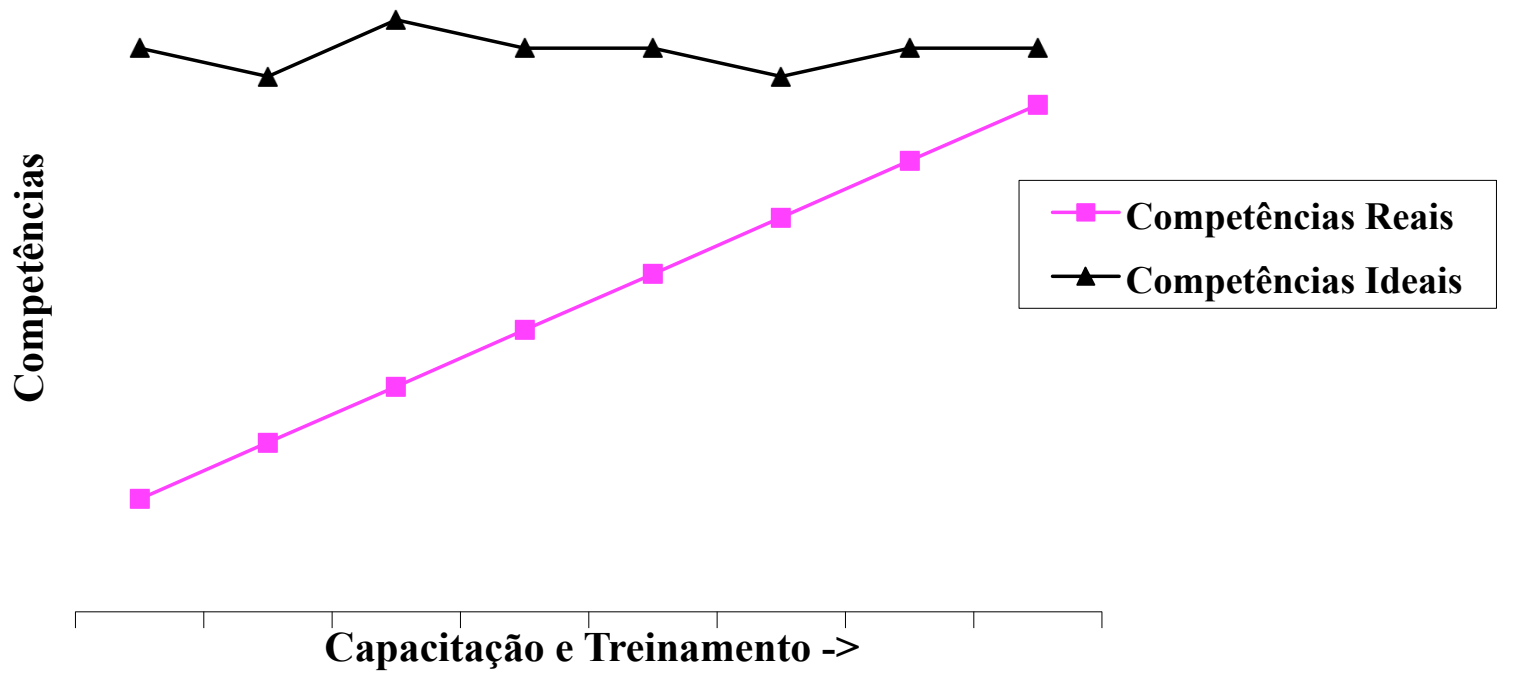

Fonte: Elaboração Própria com base em Coelho (2004).

As competências reais (status dos indivíduos) dentro da organização são identificadas mediante avaliações. Um dos métodos de avaliação é o de múltiplas 
fontes de avaliação. Segundo Leme (2005) este tipo de avalição tem uma grande vantagem porque é possível eliminar distorções ou até mesmo discriminações que uma única fonte de informação pode gerar. Neste método existem vários tipos de avaliações, como: auto avaliação, avaliação superior, avaliação externa (clientes). Com a avaliação conjunta, distorções podem ser evitadas, como a do colaborador se supervalorizar na auto avaliação, ou o superior hierárquico ter a intenção de prejudicar o avaliado. Quanto mais pessoas avaliando, melhor, pois a média das avaliações representará melhor a realidade. Neste contexto, muitas informações são geradas neste método.

Identificadas as competências necessárias para o sucesso da organização, no modelo de Gestão de Pessoas por Competências, os colaboradores são continuadamente estimulados a se desenvolver, com objetivo de atingir as competências a nível de indivíduo e consequentemente no nível da organização. As competências e objetivos organizacionais, o status dos indivíduos no processo de atingir as competências necessárias das organizações são fontes de informações que estão em constante transformação.

\section{Relações no campo da Ciência da Informação}

Nesta seção será conceituado Informação, Ciência da Informação e o tema Gestão de Pessoas por Competência será relacionado aos conceitos de autores da área como Buckland (1991), Capurro (2010), entre outros.

O conceito de informação é bastante amplo e difuso, onde diversos autores comentam o assunto. Capurro e Hjorland (2007, p. 187) afirmam que "Informação é qualquer coisa que é de importância na resposta a uma questão. Qualquer coisa pode ser informação". Estes autores também comentam que a definição de informação deve ser compreendida em relação às necessidades de grupos-alvos, na prática. E o que é Ciência da Informação?

Ciência da Informação é a disciplina que investiga as propriedades e o comportamento informacional, as forças que governam os fluxos de informação, e os significados do processamento da informação, visando à acessibilidade e a usabilidade ótima (BORKO, 1968, p. 1).

Buckland (1991), identifica três abordagens para compreender a informação: Informação-como-processo (modificação daquilo que conhece quando alguém é 
informado), informação-como-conhecimento (o que é percebido na "informaçãocomo-processo") e informação-como-coisa (atribuído aos objetos, assim como dados para documentos; algo informativo).

Ao relacionar o modelo de Gestão de Pessoas por Competências aos conceitos de Buckland sobre informação, podemos identificar o uso da informaçãocomo-processo e informação-como-conhecimento. Dentro do modelo, encontramos vários fluxos de informação que seguem um roteiro pré-determinado.

As competências dos colabores são avaliadas, gerando informações sobre o status atual que são comparadas com as competências desejadas. Encontrando divergências, o modelo propõe ajustes, como capacitações e treinamento. Em cada fase o usuário da informação sofre uma modificação de seu conhecimento (processo da informação transformando o conhecimento).

O resultado deste processo (informação-como-conhecimento) permite a este usuário/gestor tomar decisões se deve ou não tomar atitudes para o desenvolvimento de sua organização.

A Figura 1, a seguir, representa uma parte do fluxo das informações neste processo.

Figura 1: Fluxo de Informações na Gestão de Pessoas por Competências

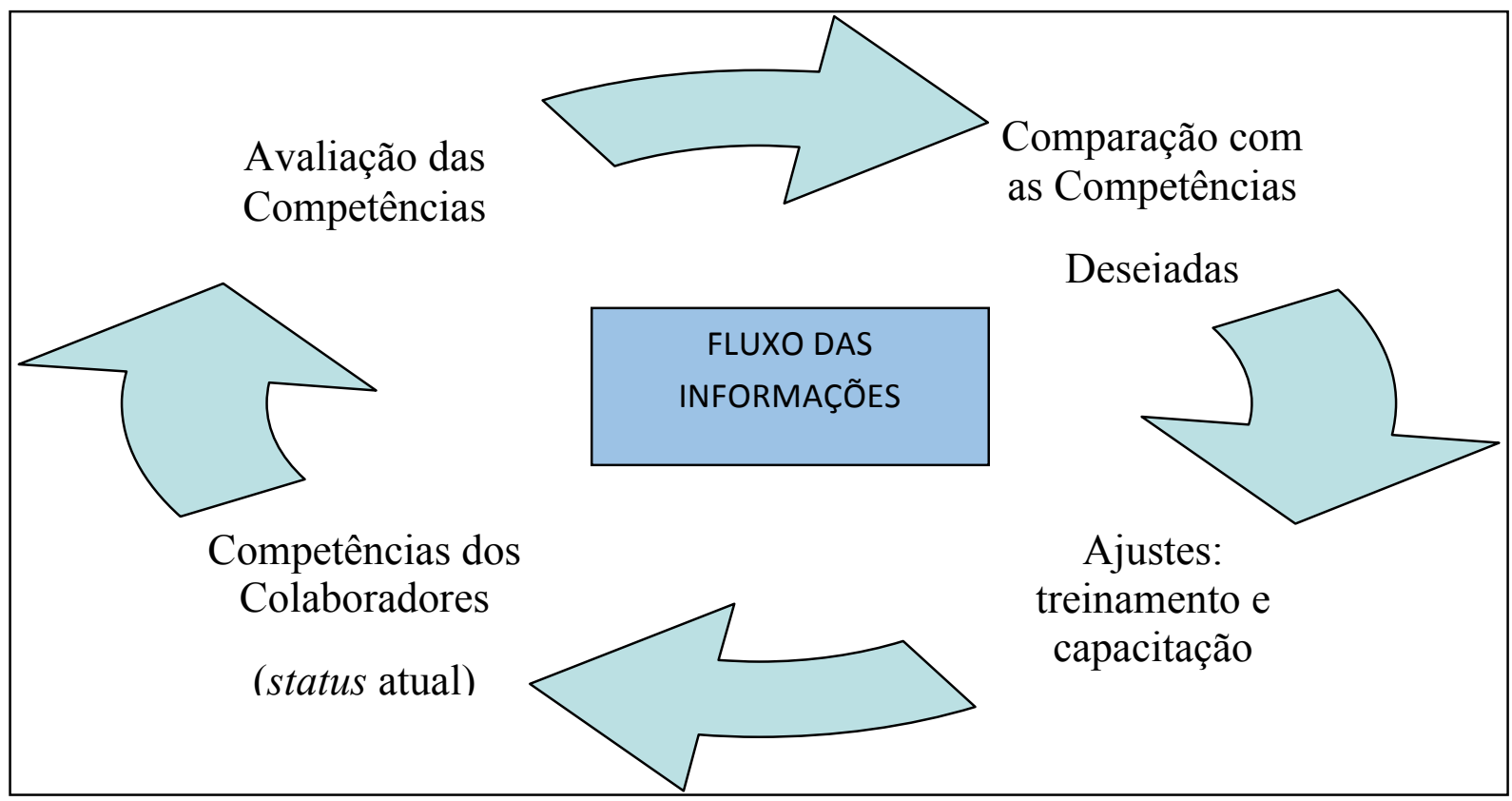

Fonte: Elaboração Própria com base em Coelho (2004) e Leme (2005). 
Complementando o conceito de "informação-como-processo", Choo (2003, p. 107) faz referência ao uso da informação que "[...] envolve a seleção e o processamento da informação, de modo a responder a uma pergunta, resolver um problema, tomar uma decisão, negociar uma posição ou entender uma situação". Baseado no fluxo de informações da Figura 1 e considerando a referência ao uso da informação proposta por Choo (2003), as perguntas implícitas no fluxo são: Quais as competências dos colaboradores (status atual)? Como avaliar estas competências? Estas competências estão de acordo com as competências desejadas pela organização? Que medidas a organização deve tomar para ajustar estas competências? Para cada pergunta existe uma informação/resposta que, após seu processamento, se transformará numa "informação-como-conhecimento" dentro do usuário desta informação.

Outra abordagem da Ciência da Informação foi descrita por Capurro (2010) que identificou três paradigmas: paradigma físico, paradigma cognitivo e paradigma social. A Gestão de Pessoas por Competências pode estar relacionada aos três paradigmas, entretanto está mais próxima dos paradigmas cognitivo e social.

O paradigma cognitivo está relacionado ao intelecto, aos processos mentais durante o uso da informação. Neste estudo ele está relacionado a identificação das competências reais dos indivíduos (status) e processamento destas informações visando sua compreensão e decisão sobre que atitudes serão necessárias para a adequação ao que a organização espera.

A Gestão de Pessoas por Competência também pode ser relacionada com o paradigma social, uma vez que dentro de uma organização, as informações são processadas e interpretadas de acordo com a cultura organizacional em que estão inseridas. Os indivíduos que analisam e processam as informações, uma vez inseridos no contexto organizacional, são influenciados por este meio. A cultura organizacional tem um papel importante na interpretação das informações. Segundo Capurro (2010, p. 10) ocorre "uma integração da perspectiva individualista e isolacionista do paradigma cognitivo dentro de um contexto social no qual diferentes comunidades desenvolvem seus critérios de seleção e relevância". Baseado no paradigma social pode-se afirmar que duas organizações com objetivos e competências semelhantes podem interpretar suas informações de forma distintas, dependendo de sua cultura organizacional. 
Esta forma distinta de utilizar e interpretar as informações descritas por Capurro (2010) perante o paradigma social não representa propriamente um problema para as organizações, visto que cada organização utiliza suas informações dentro do contexto social em que está inserida. Entretanto, existem situações em que as informações podem sofrer distorções e não representar a realidade. Shannon e Weaver (1975) desenvolveram a teoria matemática da comunicação que previa que o ruído nas mensagens pode atrapalhar a transmissão das informações (comunicação). Este ruído pode perturbar a acessibilidade e usabilidade das informações, colocando em cheque sua qualidade. Esta situação deve ser evitada para evitar distorções nas decisões dos gestores. Procedimentos podem ser adotados pelas organizações para evitar a perca da qualidade das informações, como por exemplo, o método de avaliações múltiplas citado na seção anterior procura utilizar várias fontes de informações sobre a situação atual dos colaboradores para tentar representar a situação real da organização de forma mais fidedigna, evitando ruídos e distorções.

Mecanismos e processos que produzam informações de qualidade devem ser desenvolvidos e incentivados dentro das organizações, pois, conforme Beal (2012) afirma, a qualidade da informação irá influenciar a qualidade das decisões dos tomadores, assim como sua capacidade de interpretá-la e usá-la irá determinar se a melhor decisão será tomada. Decisões baseadas em informações sem qualidade (com ruídos e distorções) podem diminuir o desempenho e a eficácia das organizações, até mesmo, comprometer sua permanência no mercado.

A parte de Gestão de Informações ainda está em desenvolvimento. Os temas treinamento e sistema de informação ainda serão desenvolvidos no decorrer do mestrado.

\section{PROCEDIMENTOS METODOLÓGICOS}

O estudo será desenvolvido inicialmente por pesquisa exploratória para diagnosticar e identificar a atual situação do órgão federal de segurança quanto ao registro e gestão das informações de treinamento dos servidores.

Este diagnóstico será feito com gestores de órgãos centrais em Brasília correlatos ao tema da proposta através de entrevista semiestruturada. Também será 
enviado questionário estruturado com perguntas fechadas e abertas para algumas unidades do órgão, tentando abranger uma unidade em cada ente federativo.

A pesquisa não poderá abranger todas as unidades do órgão devido sua área de atuação nacional com diversas unidades espalhadas pelo país. Por este motivo será determinado uma amostragem das unidades que serão foco da pesquisa.

Também se verifica a necessidade de um diagnóstico benchmarking com algum órgão de segurança estadual para verificar como ele faz a gestão de informações sobre os treinamentos de seus servidores

A pesquisa bibliográfica será realizada para identificação das melhores técnicas e meios para desenvolvimento do projeto de sistema de gestão das informações, bem como fundamentar os resultados obtidos e propostas.

As atividades previstas para o segundo semestre de 2018 são: pesquisa diagnóstica para identificar a atual situação do órgão, participar das disciplinas faltantes do programa de Pós-graduação e complemento da fundamentação teórica. Para todo o ano de 2019 está prevista o desenvolvimento da dissertação, sendo que no primeiro semestre será realizada a qualificação e no segundo semestre a defesa do trabalho.

\section{CONSIDERAÇÕES PARCIAIS}

Por se tratar de um estudo inicial, até o momento da pesquisa, foi desenvolvido apenas parte da fundamentação teórica e foi constatado que a Ciência da Informação e o modelo de Gestão de Pessoas por Competências tem relação com os objetivos.

Com o término da pesquisa, espera-se desenvolver um estudo e projeto de sistema que possibilite o gerenciamento das informações sobre treinamento dos servidores de órgãos de segurança pública, proporcionando aos gestores recursos para tomada de decisões quanto ao planejamento e adequação das atividades da instituição.

Este sistema também facilitará o atendimento da Portaria Interministerial $n^{\circ}$ 4.226/2010 porque permitirá uma visão fidedigna da real situação do efetivo em relação aos treinamentos efetuados ou a falta deles.

\section{REFERÊNCIAS}


BEAL, Adriana. Gestão Estratégica da Informação. São Paulo: Atlas, 2012.

BORKO, Harold. Ciência Da Informação: O Que É Isto? American Documentation v. 19, n. 1, p. $3-5,1968$.

BRASIL. Ministério de Estado da Justiça e Ministério de Estado Chefe da Secretaria de Direitos Humanos da Presidência da República. Portaria Interministerial $\mathbf{n}^{\mathbf{0}}$ 4.226 de 31/12/2010. Estabelece Diretrizes sobre o Uso da Força pelos Agentes de Segurança Pública. Diário Oficial da União de 03/01/2011 (nº 1, Seção 1, pág. 27).

BUCKLAND, Michael K. Information as thing. Journal of the American Society for Information Science v. 42, n. 5, p. 351-360, 1991.

CAPURRO, Rafael. Epistemologia e ciencia da informação. v. 14, n. 1985, p. 1-21 , 2010. Disponível em: <http://www.capurro.de/enancib_p.htm>. Acesso em: 03 de maio de 2018.

CAPURRO, Rafael; HJORLAND, Birger. O Conceito da Informação. Perspectivas em Ciência da Informação v. 12, n. 1, p. 148-207, 2007. Disponível em: $<$ http://bogliolo.eci.ufmg.br/downloads/CAPURRO.pdf>. Acesso em: 03 de maio de 2018.

CHIAVENATO, Idalberto. Recursos humanos: o capital humano das organizações. 8. ed. São Paulo: Atlas, 2004.

$\mathrm{CHOO}$, Chun Wei. A organização do conhecimento: como as organizações usam a informação para criar significado, construir conhecimento e tomar decisões. Tradução de Eliana Rocha. 2 ed. São Paulo: SENAC, 2003.

COELHO, Espartaco Madureira. Gestão do conhecimento como sistema de gestão para o setor público. Revista do Serviço Público, n 1-2, p. 89-115, 2004. Disponível em: <https://revista.enap.gov.br/index.php/RSP/article/view/247/529>. Acesso em: 03 de maio de 2018.

FERREIRA, Aurélio Buarque de Holanda. Novo Aurélio Século XXI: o dicionário da língua portuguesa. 3 ed. Rio de Janeiro: Nova Fronteira, 1999.

FISCHER, André Luiz. Um resgate conceitual e histórico dos modelos de gestão de pessoas: As pessoas na organização. São Paulo: Gente, 2002.

FLEURY, Maria Tereza Leme; FLEURY, Afonso. Construindo o conceito de competência. Rev. adm. contemp., Curitiba , v. 5, n. spe, p. 183-196, 2001. Disponível em: <http://www.scielo.br/scielo.php?script=sci_arttext\&pid=S141565552001000500010\&lng=en\&nrm=iso>. Acesso em: 20 abr. 2018.

GUIMARÃES, Arthur. Falta de treinamento e cultura atrasada estão por trás de erros policiais, dizem especialistas. São Paulo, 2010. Disponível em: <https://noticias.uol.com.br/cotidiano/ultimas-noticias/2010/07/27/profissionais-miojo- 
e-cultura-atrasada-estao-por-tras-dos-erros-policiais-dizem-especialistas.htm>. Acesso em: 31 jul. 2018.

LEME, Rogério. Aplicação prática de gestão de pessoas por competências, mapeamento, treinamento, seleção, avaliação e mensuração de resultados de treinamento. Rio de Janeiro: Qualitymark, 2005.

OLIVEIRA, Marlene; BERTUCCI, Maria da Graça Eulálio de Souza. A pequena e média empresa e a gestão da informação. Informação \& Sociedade: Estudos v. 13, p. 65-87, 2003. Disponível em: <http://www.brapci.inf.br/v/a/1403>. Acesso em: 03 de maio de 2018.

RABAGLIO, Maria Odete. Seleção por competência. 5. ed. São Paulo: Educador, 2001.

RUANO, Alessandra Martinewski. Gestão por competências, uma perspectiva para a consolidação da gestão estratégica de recursos humanos. Rio de Janeiro: Qualitymark, 2003.

SHANNON, Claude Elwood; WEAVER, Warren. A teoria matemática da comunicação. Tradução de Orlando Agueda. São Paulo: Difel, 1975. 